\title{
Extracorporeal photopheresis in a one-year-old child with low body weight
}

\author{
Krzysztof Czyżewski ${ }^{*}$ Robert Dębski, Mariusz Wysocki, Jan Styczyński \\ Department of Pediatric Hematology and Oncology, Collegium Medicum in Bydgoszcz, Nicolaus Copernicus University in Toruń, \\ Antoni Jurasz University Hospital 1, Bydgoszcz, Poland
}

Graft-versus-host disease (GvHD) is a severe complication of allogeneic hematopoietic cell transplantation (HCT). Extracorporeal photopheresis (ECP) is considered to be a second-line treatment for steroid-refractory acute and chronic GvHD (a/cGvHD) [1].

Several modifications of the conventional ECP approach have been developed, including ECP-treated enriched or depleted cell populations, ECP-treated allogeneic cells, cryopreservation of ECP-treated cells, and mini-ECP [2, 3]. The use of conventional ECP can be particularly challenging for very young children with low body weight because of limited extracorporeal volume, difficulty in maintaining intravascular fluid balance, lack of adequate vascular access, and the patient's inability to tolerate the lengthy procedure [4].

Response to ECP was definied as:

- a complete response (CR) if GvHD signs in all organs resolved;

- a partial response (PR) if greater than $50 \%$ resolution was reached without other, additional immunosuppression;

- no response if patients did not improve or required additional immunosuppressive agents.

Response is usually assessed one and three months after the start of ECP. ECP is usually discontinued in patients who attain a CR or a steroid dose below $0.5 \mathrm{mg} / \mathrm{kg}$ body weight, or if patients have a lack of response or develop progression to aGVHD [1].

The objective of this report was to present the feasibility and safety of ECP in a one-year-old child with a body weight of $8.5 \mathrm{~kg}$.

A 10-month-old boy with severe congenital neutropenia with ELANE gene mutation had HCT from a female matched unrelated donor, $\mathrm{AB} 0 / \mathrm{Rh}$ compatible blood group, after conditioning with busulfan ( $4 \times 5.1 \mathrm{mg} / \mathrm{kg} /$ day, from -5 to -2$)$, fludarabine ( $4 \times 40 \mathrm{mg} / \mathrm{m}^{2} /$ day, from -5 to -2 ), and rabbit thymoglobuline $(4 \times 2.5 \mathrm{mg} / \mathrm{kg}$ bw/day, from -5 to -2$)$. Bone marrow was transplanted with $4.53 \times 10^{6} \mathrm{CD} 34$ cells/ $/ \mathrm{kg}$. For GvHD prophylaxis, the patient was administered with cyclosporine and mycofenolate mofetil.

After five days, the patient received rituximab for prophylaxis of post-transplant lymphoproliferative disorder [5]. He developed skin hyperacute $\mathrm{GGvHD}_{\mathrm{IV}}{ }^{\circ}$ in the first week after HCT, treated with methylprednisolone $2 \mathrm{mg} / \mathrm{kg}$ body weight, and steroid resistance was observed. After 10 days, mesenchymal stem cells (MSC) were administered with good response and complete resolution of skin changes. Cyclosporine doses were adjusted to keep his blood trough concentration close to $200 \mathrm{ng} / \mathrm{mL}$, and steroid administration was gradually withdrawn. Neutrophil recovery occurred after 23 days, and platelet recovery after 12 days. The donor chimerism on day +30 was $99 \%$. After 28 days, the skin symptoms of aGvHD had recurred, and GvHD of the gastrointestinal tract (GI) was suspected. Again, the response to increased doses of steroids was poor. The baby was administered a second dose of MSC with significant improvement but an incomplete response. Moderate skin and Gl symptoms persisted in spite of steroid administration. Meanwhile, symptoms of Cushing syndrome appeared, and therefore ECP treatment was started after 76 days.

We used 'in-line' ECP with CellEX Photopheresis System (Therakos UK Ltd., Mallinckrodt Pharmaceuticals Company, UK). Owing to the extremely low body weight of the patient, a blood prime procedure with $\mathrm{ABO} / \mathrm{Rh}$ compatible packed red blood cells in a single needle mode was carried out

\footnotetext{
*Address for correspondence: Krzysztof Czyżewski, Department of Pediatric Hematology and Oncology, Collegium Medicum, Nicolaus Copernicus University Toruń, Skłodowskiej-Curie 9, 85-094, Bydgoszcz, Poland, phone: +4852585 4860, fax: +48 52585 4087, e-mail: k.czyzewski@cm.umk.pl 
A

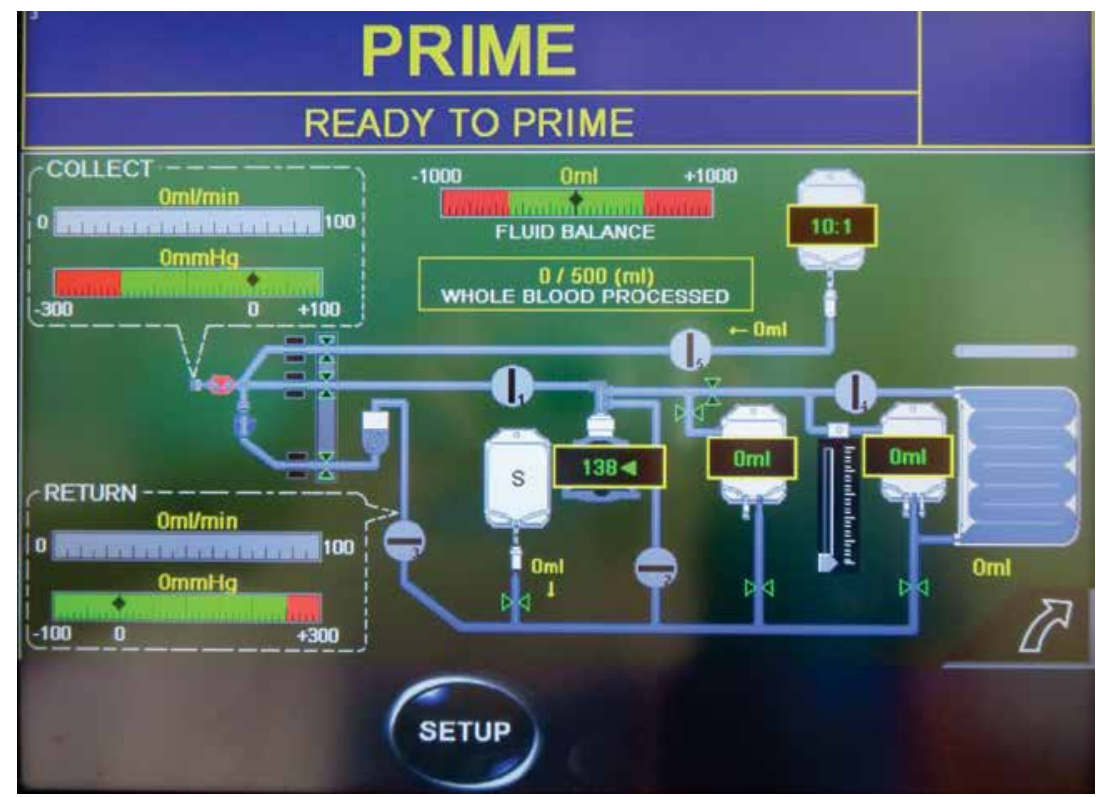

B

\begin{tabular}{|c|c|c|c|c|c|c|c|c|}
\hline \multirow[t]{2}{*}{ Parameter } & \multicolumn{2}{|c|}{ Before ECP } & \multicolumn{2}{|c|}{1 month after ECP } & \multicolumn{2}{|c|}{3 months after ECP } & \multicolumn{2}{|c|}{7 months after ECP } \\
\hline & [\%] & $\ln 1 \mu \mathrm{L}$ & [\%] & $\ln 1 \mu \mathrm{L}$ & [\%] & $\ln 1 \mu \mathrm{L}$ & [\%] & $\ln 1 \mu \mathrm{L}$ \\
\hline White blood cells & - & 250 & - & 3,700 & - & 24,780 & - & 14,060 \\
\hline Lymphocytes & 66.0 & 165 & 18.0 & 675 & 13.0 & 3,221 & 20.0 & 2,812 \\
\hline CD19 & 0.9 & 1 & 0.0 & 0 & 2.2 & 71 & 2.8 & 79 \\
\hline $\mathrm{CD} 2$ & 81.5 & 134 & 88.7 & 599 & 86.8 & 2,796 & 84.4 & 2,373 \\
\hline CD3 & 76.8 & 127 & 66.2 & 447 & 80.4 & 2,590 & 74.9 & 2,106 \\
\hline $\mathrm{CD} 4$ & 66.0 & 109 & 56.4 & 381 & 61.7 & 1,987 & 45.2 & 1,271 \\
\hline $\mathrm{CD8}$ & 12.0 & 20 & 12.0 & 81 & 19.8 & 638 & 35.3 & 993 \\
\hline $\mathrm{CD} 3+4+$ & 65.5 & 108 & 56.3 & 380 & 61.0 & 1,965 & 44.8 & 1,260 \\
\hline $\mathrm{CD} 3+8+$ & 12.0 & 20 & 12.0 & 81 & 19.3 & 622 & 34.7 & 976 \\
\hline CD3-16+56+ & 0.5 & 1 & 12.1 & 82 & 1.7 & 55 & 11.7 & 329 \\
\hline CD3-CD8+ & 0.7 & 1 & 2.9 & 20 & 0.6 & 19 & 5.3 & 149 \\
\hline CD4/CD8 & 5.5 & - & 4.7 & - & 3.1 & - & 1.3 & - \\
\hline $\mathrm{CD} 3+4+/ \mathrm{CD} 3+8+$ & 5.5 & - & 4.4 & - & 3.2 & - & 1.3 & - \\
\hline
\end{tabular}

Figure 1. Extracorporeal photopheresis (ECP): A. ECP control monitor; B. Patient lymphocyte subpopulations before and after ECP

(Figure 1A). After blood prime, we connected to the patient and switched into double needle mode with simultaneous blood drawing and returning by double lumen inguinal venous catheter. The drawing/returning speed was set at $5-10 \mathrm{~mL} / \mathrm{min}$.

As part of the treatment, $200 \mathrm{~mL}$ of the patient's whole blood was processed. For anticoagulation, heparin was used. Eventually, the patient received approximately 75 units of heparin during each ECP procedure. During the whole collection procedure, the patient's vital signs were monitored. The buffy coat was extracted and 8-methoxypsoralen was injected directly into the treatment bag. The cells were afterwards irradiated in the ultraviolet (UVA) photoactivation module, as required by the protocol. The UVA-irradiated cells were then infused back into the patient.

The total volume of irradiated cells was approximately $120 \mathrm{~mL}$, and this was infused slowly over 30 minutes to prevent fluid overload. At the end of the procedure, the patient's fluid balance was positive, at $15 \%$ of total body blood volume (within the accepted protocol). The patient tolerated both the blood collection and infusion of irradiated 
cells; no adverse events were observed. The overall time of the whole procedure from the first blood collection to the end of reinfusion of treated buffy coat to the patient was approximately 120 minutes.

Two cycles of ECP on consecutive days were performed. Due to bacteremia, subsequent cycles were postponed. Four weeks after ECP was performed, steroids were reduced to a dose of $0.5 \mathrm{mg} / \mathrm{kg}$ body weight. Lymphocyte subpopulations were slowly normalising (Figure 1B). We could not determine CR/PR of GvHD. However, the success of the procedure carried out shows that ECP is feasible and safe in a baby of $8 \mathrm{~kg}$ body weight.

\section{Acknowledgments}

The authors wish to thank the team of nurses at the HCT unit led by Ewa Dembna for their excellent patient care.

\section{Authors' contributions}

JS, KC - study design. KC, JS - data analysis and interpretation. KC, JS - manuscript writing. JS - administrative support. All authors - provision of important clinical data, data check, and final approval.

\section{Conflicts of interest}

The authors declare no conflict of interest related to this study.

\section{Financial support \\ None.}

\section{Ethics}

The work described in this article has been carried out in accordance with the Code of Ethics of the World Medical Association (Declaration of Helsinki) for experiments involving humans; EU Directive 2010/63/EU for animal experiments; Uniform Requirements for Manuscripts submitted to Biomedical Journals.

\section{References}

1. Worel $\mathrm{N}$, Lehner $\mathrm{E}$, Führer $\mathrm{H}$, et al. Extracorporeal photopheresis as second-line therapy for patients with acute graft-versus-host disease: does the number of cells treated matter? Transfusion. 2018; 58(4): 1045-1053, doi: 10.1111/trf.14506, indexed in Pubmed: 29446444.

2. Raval JS, Ratcliffe NR. Extracorporeal photopheresis and personalized medicine in the 21st century: The future's so bright! J Clin Apher. 2018; 33(4): 461-463, doi: 10.1002/jca.21633, indexed in Pubmed: 29736969.

3. Matic T, Bojanic I, Mazic S, et al. An automated mini buffy coat preparation method for use in mini extracorporeal photopheresis treatment of graft-vs-host-disease in a low body weight pediatric patient. J Clin Apher. 2019; 34(4): 468-473, doi: 10.1002/jca.21700, indexed in Pubmed: 30829417.

4. DeSimone RA, Schwartz J, Schneiderman J. Extracorporeal photopheresis in pediatric patients: practical and technical considerations. J Clin Apher. 2017; 32(6): 543-552, doi: 10.1002/jca.21534, indexed in Pubmed: 28304115.

5. Styczynski J, Tridello G, Gil L, et al. Prognostic impact of Epstein-Barr virus serostatus in patients with nonmalignant hematological disorders undergoing allogeneic hematopoietic cell transplantation: the study of Infectious Diseases Working Party of the European Society for Blood and Marrow Transplantation. Acta Haematol Pol. 2020; 51(2): 73-80, doi: 10.2478/ahp-2020-0015. 